\title{
GLOBAL RESISTANCE FACTOR FOR THE BURNOUT RESISTANCE OF CONCRETE SLABS EXPOSED TO PARAMETRIC FIRES
}

\author{
Thomas Thienpont $^{1}$, Ruben Van Coile ${ }^{2}$, Balsa Jovanovic ${ }^{3}$, Wouter De Corte ${ }^{4}$, Robby Caspeele ${ }^{5}$
}

\begin{abstract}
Although traditionally the fire resistance rating of concrete elements is determined through standardized tests or tabulated data, there is a growing trend towards the use of performance-based approaches to evaluate structural behaviour during or after a fire. The safety format to be applied with these advanced numerical evaluations is however unclear. In this paper, the applicability of the concept of a global resistance factor (GRF) safety format is explored for simply supported concrete slabs exposed to the Eurocode parametric fire curve for a wide range of parameters. The safety of the slab is evaluated in relation to its ability to withstand a complete burnout scenario, i.e. its ability to resist the applied loads throughout the entire duration of a fire including the cooling phase. Using a full-probabilistic model, the required GRF is numerically derived for a specified target safety level in case of fire. Additionally, a calculation method is provided which allows to determine the GRF of fire exposed slabs for any given compartment through the use of a reference compartment and equivalency equations.
\end{abstract}

Keywords: Structural fire safety; Burnout resistance; Concrete slab; Global resistance factor

\section{INTRODUCTION}

Traditional structural fire design typically employs the fire resistance time $R$ as the primary metric to evaluate whether a structural member can maintain its functionality in a predefined fire exposure scenario. Typically, this fire scenario is defined by the ISO 834 [1] or ASTM E119 [2] time-temperature relationship. This principle forms the basis of many design practices, and is applied in several design codes such as EN 1992-1-2:2004 [3]. However, recent investigations have highlighted that designing concrete structures using these traditional methods has some major shortcomings.

Firstly, these methods fail to encompass essential information about the structural behaviour in a realistic fire scenario. Apart from a heating phase, real compartment fires are also characterized by a cooling phase. Herein, as the available fuel in the compartment is used up, the temperature decreases back to ambient conditions. Research has shown that, in a design, considering a complete burnout scenario with a cooling phase is indispensable to identify (delayed) failure modes that would otherwise remain undetected $[4,5]$. In the case of reinforced concrete (RC) members, such a delayed failure can occur due to the fact that the

\footnotetext{
${ }^{1} \mathrm{PhD}$ Student, Department of Structural Engineering and Building Materials, Ghent University, Ghent, Belgium. e-mail: thomas.thienpont@ugent.be, ORCID: https://orcid.org/0000-0003-1466-3377

${ }_{2}^{2}$ Professor, Department of Structural Engineering and Building Materials, Ghent University, Ghent, Belgium. e-mail: ruben.vancoile@ugent.be, ORCID: https://orcid.org/0000-0002-9715-6786

${ }^{3} \mathrm{PhD}$ Student, Department of Structural Engineering and Building Materials, Ghent University, Ghent, Belgium. e-mail: balsa.jovanovic@ugent.be, ORCID: https://orcid.org/0000-0001-5200-5848

${ }^{4}$ Professor, Department of Structural Engineering and Building Materials, Ghent University, Ghent, Belgium. e-mail: wouter.decorte@ugent.be, ORCID: https://orcid.org/0000-0002-9416-3593

${ }^{5}$ Professor, Department of Structural Engineering and Building Materials, Ghent University, Ghent, Belgium. e-mail: robby.caspeele@ugent.be, ORCID: https://orcid.org/0000-0003-4074-7478
} 
maximum temperatures in the section can be reached a significant time after the beginning of the cooling phase [6]. In contrast to steel members, due to the high thermal capacity and relatively low thermal conductivity of concrete, it takes quite some time for the inner layers of a section to heat up. As a consequence, the highest temperatures in the embedded steel reinforcement are reached long after the onset of the cooling phase. This is especially relevant in RC beams and slabs loaded in bending, which rely heavily on the steel tensile strength to maintain their load bearing capacities. To avoid delayed failure of $\mathrm{RC}$ slabs it is indispensable to evaluate the change in carrying capacity throughout the entire duration of the fire scenario. Therefore this article discusses the concept of burnout resistance of RC slabs, as it allows for designing structural members to survive the total duration of the fire until complete burnout, thus providing clarity on the expected performance of the structure in case of a real fire.

A second shortcoming stems from the fact that the input values for the material properties and loads used in structural design are usually based on characteristic values, combined with partial factors. This approach, which is commonly referred to as being semi-probabilistic, ensures an appropriately low probability of failure, while limiting the complexity of the analysis. It provides a trade-off between simplicity and accuracy, and has proven very useful in normal design situation. However, for fire safety engineering applications, no generally accepted safety targets and semi-probabilistic design methodologies based on such explicit target levels currently exist. In search of a suitable safety format, several methods have been proposed. For the case of structural fire design, which nowadays typically involves the use of computationally demanding finite element (FE) models, a full-probabilistic approach quickly becomes unfeasible. The application of these FE models requires the definition of a safety format which relies on a limited (ideally a single) evaluation of the computationally expensive model. Therefore several studies have proposed the use of a global resistance factor (GRF) safety format for numerically expensive models [710]. In a GRF based safety format, the design resistance $R_{d}$ is obtained from a single evaluation with mean values for the stochastic input parameters. This constitutes a (first-order Taylor) approximation for the average resistance $\mu_{R}$ and which is then divided by a GRF $\gamma_{R}$, to obtain the design value for the structural resistance $R_{d}$, see Eq. (1).

$$
R_{d}=\frac{\mu_{R}}{\gamma_{R}}
$$

Considering the above, the main objective of this article is to evaluate and calibrate the GRF for the burnout resistance of simply supported RC slabs. The methods presented in this article are intended as a stepping stone towards the development of more elaborate GRF based safety formats, for complex geometries and advanced numerical tools.

\section{BURNOUT RESISTANCE OF A RC SLAB}

In the following, a method is presented to evaluate the burnout resistance of simply supported RC slabs exposed to natural fires. First, an analytical equation for the bending capacity during fire is introduced. Subsequently, in Section 2.2, the concept of burnout resistance is summarily discussed and illustrated for a reference compartment exposed to several natural fires.

\subsection{Resistance of RC slab during fire}

The load bearing capacity of a simply supported RC slab exposed to fire at the bottom side, can be expressed in terms of the bending moment capacity at the mid-span of the slab. In this article, the evolution of the bending moment capacity $M_{R, f i}$, during the course of a fire is calculated using a two-step procedure.

First, the temperature evolution inside the slab is calculated using a numerical 1D-temperature ingress model. The details on the temperature calculation procedure are described in detail in a previous study by the authors [6]. Figure 1 depicts the temperature evolution in a $200 \mathrm{~mm}$ concrete slab exposed to a Eurocode parametric fire (red curve) [11]. This time-temperature curve corresponds to a fire in a $10 \mathrm{~m} \times 10 \mathrm{~m} \times 3 \mathrm{~m}$ compartment, with an opening factor $O=0.05 \mathrm{~m}^{1 / 2}$ (a measure for the ventilation properties), fire load density $q_{f}=800 \mathrm{MJ} / \mathrm{m}^{2}$ (the amount of combustibles in the compartment) and thermal effusivity $b=$ 
$1450 \mathrm{~J} / \mathrm{m}^{2} \mathrm{~s}^{0.5}$. From the graph it is evident that the maximum temperature inside the solid slab (e.g. at depth $=50 \mathrm{~mm}$ ) is reached long after the onset of the cooling phase. The highest temperatures in a rebar at that location, and the corresponding lowest strength, are thus reached during (or after) the fire's decay phase.

The temperature data obtained in the first step is subsequently used as input to estimate the bending moment capacity $M_{R, f i, t}$ of a RC slab section with a single layer of bottom reinforcement using a simplified expression. The expression (2) is based on Van Coile et al. [12] and was validated against more detailed numerical simulations [13].

$$
M_{R, f i, t}(a)=A_{s} k_{f y(\theta)} f_{y, 20^{\circ} \mathrm{C}}(h-a)-0.5 \frac{\left(A_{s} k_{f y(\theta)} f_{y, 20^{\circ} \mathrm{C}}\right)^{2}}{w f_{c, 20^{\circ} \mathrm{C}}}
$$

Herein, $A_{s}$ is the area of reinforcement, $k_{f y}$ is the strength retention factor for reinforcement yield stress at temperature $\theta, f_{y, 20^{\circ} \mathrm{C}}$ is the steel strength at $20^{\circ} \mathrm{C}, h$ is the slab thickness, $a$ is the rebar axis distance (i.e. concrete cover $+1 / 2$ rebar diameter), $w$ is the slab section width and $f_{c, 20^{\circ} \mathrm{C}}$ is the concrete compressive strength. Note that expression (2) takes into account the temperature dependent strength reduction of the steel reinforcement (through the factor $k_{f y} \leq 1$ ), but not for concrete. Since the slab is only exposed to elevated temperatures at the bottom, the temperature increase in the concrete at the compression side has negligible effect on the overall strength reduction for the $200 \mathrm{~mm}$ thick slab. When combining the above expression with temperature calculations for exposure to natural fire, the burnout resistance can be obtained.

\subsection{Burnout resistance}

Considering the previously presented methodology, the evolution of the bending moment capacity $M_{R, f i}$ as it changes through time during a fire scenario can be evaluated. Figure 2(b) and 3(b) each depict the bending moment resistance of an example slab, as defined in Table 1, for three Eurocode parametric fire scenarios. Figure 2(a) lists three fires curves for a compartment with a fixed opening factor $\mathrm{O}=0.05 \mathrm{~m}^{1 / 2}$. From the combination of Figure 2(a) and (b) it is clear that when the density of combustible material $q_{f}$ in the compartment increases, a certain threshold is reached at which the capacity of the slab during fire become smaller than the moments due to the self-weight and loads (i.e. demand), which ultimately means that the structure does not maintain its load-carrying capacity up to burnout. Similarly, in Figure 3, decreasing the opening factor $O$ ultimately leads to a scenario where the carrying capacity reaches a critical value and is unable to survive the entire duration of the fire scenario. A more in-depth discussion on the burnout resistance of RC slabs, along with an easily applicable design method is presented in Thienpont et al. [6]. In this article, burnout resistance $M_{R, \text { burnout }}$ is defined as the combination of parameters $O$ and $q_{f}$ for which the slab is able to withstand the entire duration of the fire.

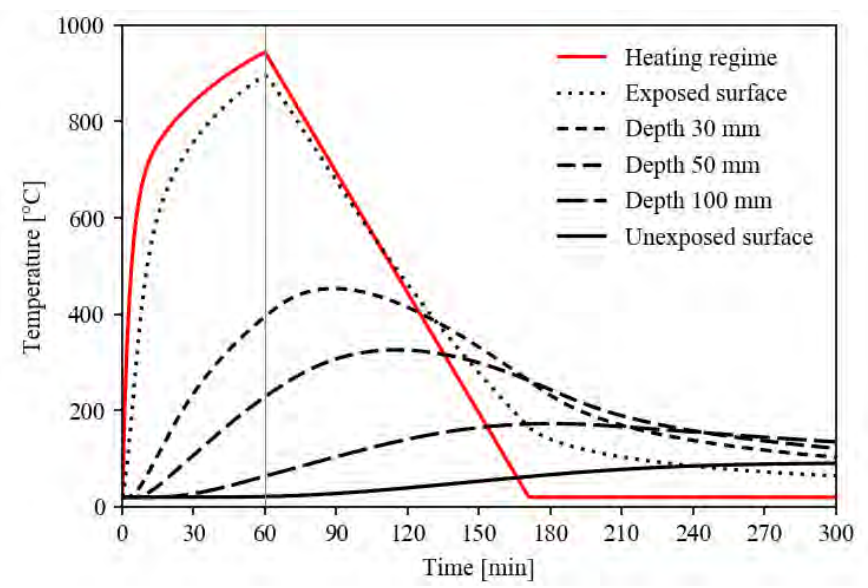

Figure 1: Temperature evolution in a $200 \mathrm{~mm}$ solid concrete slab, exposed from below to a Eurocode parametric fire

Table 1. Properties of example RC slab.

\begin{tabular}{|l|c|c|c|c|c|}
\hline height $\boldsymbol{h}$ & width $\boldsymbol{w}$ & Rebar axis distance $\boldsymbol{a}$ & Area of reinforcement $\boldsymbol{A}_{\boldsymbol{s}}$ & $\boldsymbol{f}_{\boldsymbol{c k}}$ & $\boldsymbol{f}_{\boldsymbol{y} \boldsymbol{k}}$ \\
\hline $200 \mathrm{~mm}$ & $1000 \mathrm{~mm}$ & $35 \mathrm{~mm}$ & $785 \mathrm{~mm}^{2}$ & $30 \mathrm{MPa}$ & $500 \mathrm{MPa}$ \\
\hline
\end{tabular}



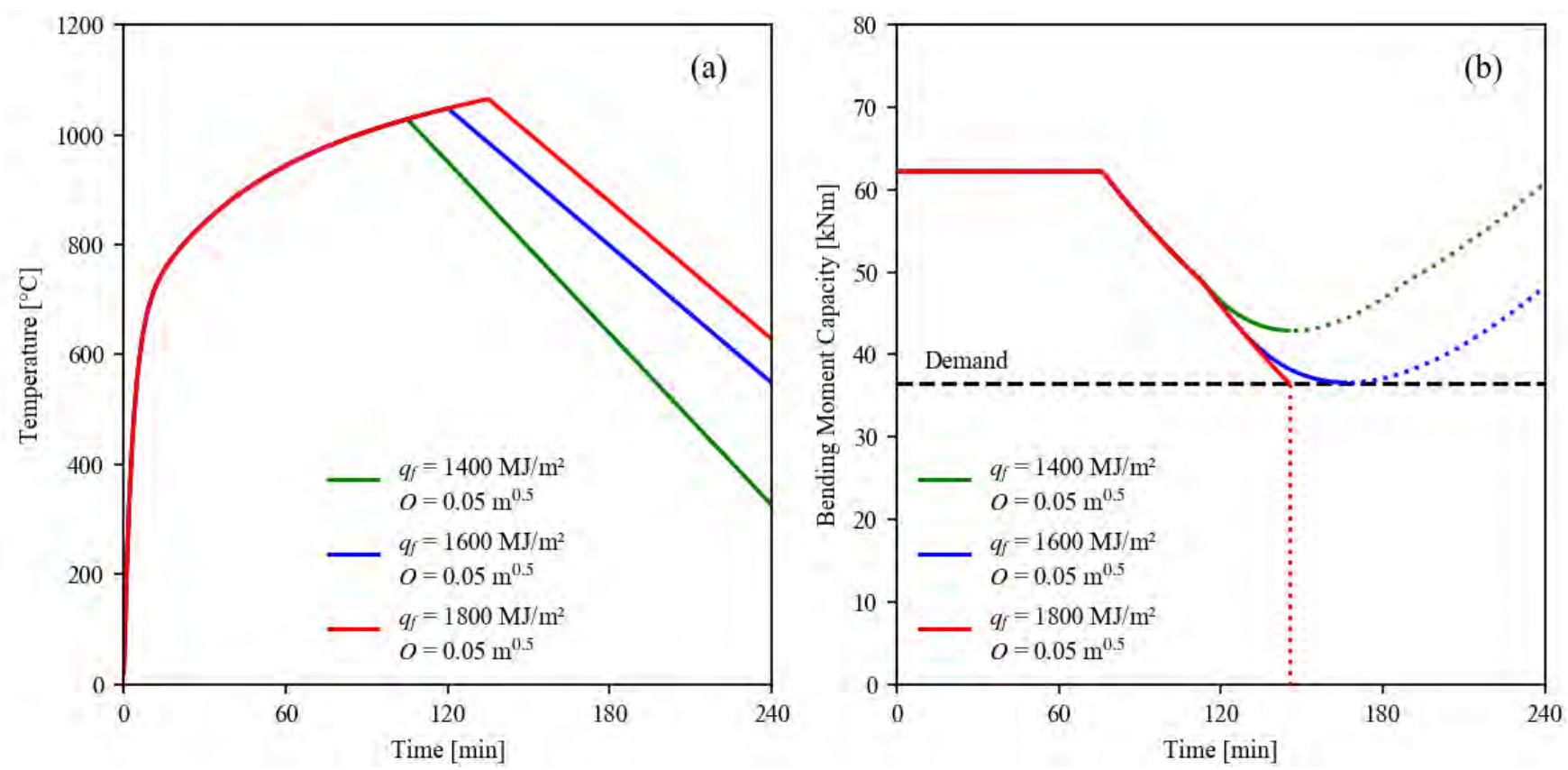

Figure 2: a) Time temperature curves for natural fires with opening factor $O=0.05$ and variable fire load density; b) evolution of bending moment capacity for the RC slab defined in Table 2, exposed to said natural fires.
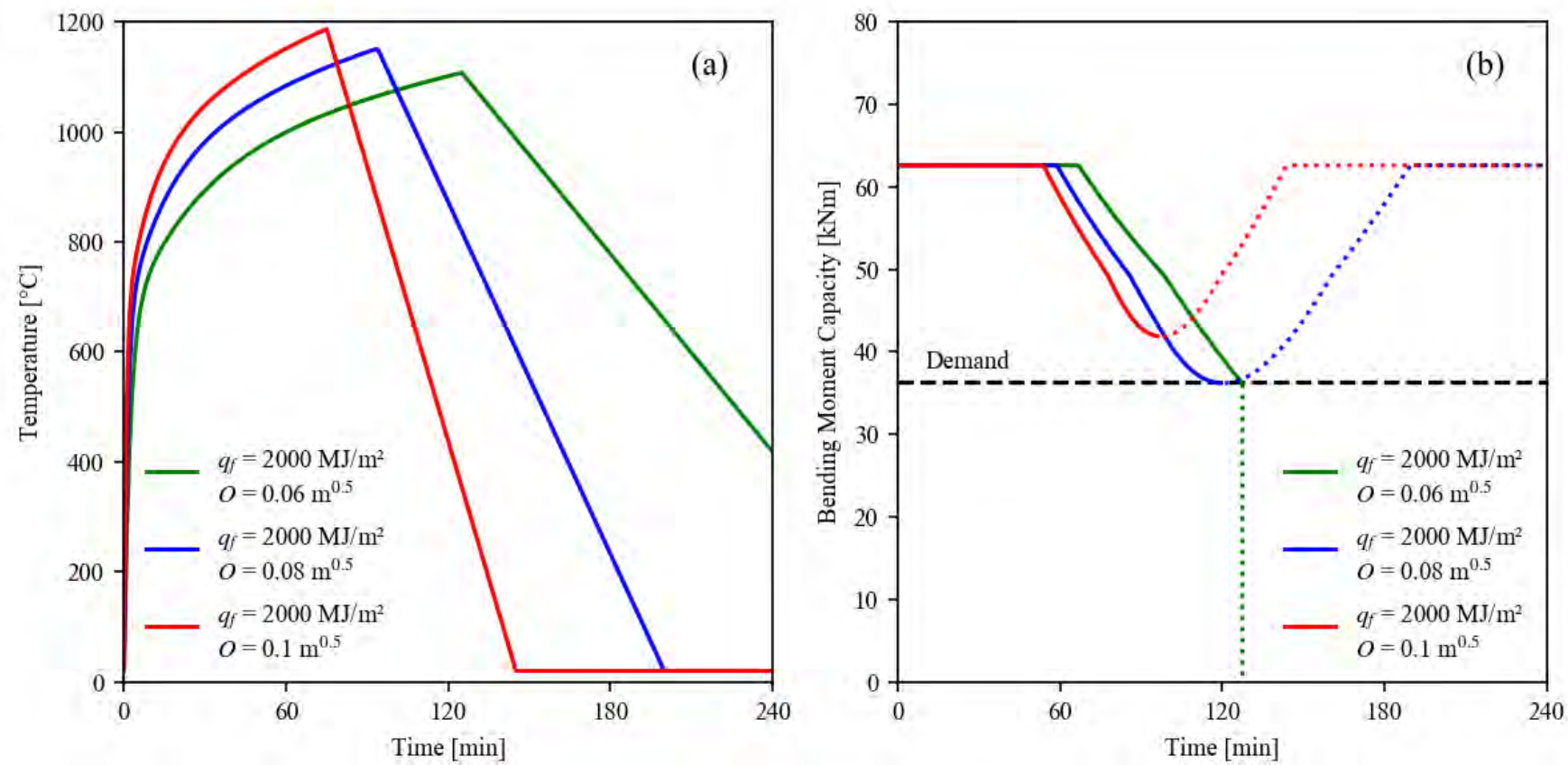

Figure 3: a) Time temperature curves for natural fires with fire load density $q_{f}=2000 \mathrm{MJ} / \mathrm{m}^{2}$ and variable opening factor; b) evolution of bending moment capacity for the RC slab defined in Table 2, exposed to said natural fires.

\section{PROBABILISTIC BENDING RESISTANCE OF FIRE EXPOSED RC SLABS}

In this section, the concept of burnout resistance is applied in a probabilistic evaluation of the bending moment capacity, thus taking into account the uncertain nature of the material properties and geometry. Next, in section 3.2, the consequences of also considering the uncertainties on the amount of combustible material, i.e. the fire load density, is discussed. Lastly, in Section 3.3, which also takes into consideration the uncertain nature of the permanent and variable loads, a set of fragility curves for the burnout resistance of RC slabs are derived. 


\subsection{Probabilistic burnout bending resistance of RC slabs for deterministic fire exposure}

The burnout evaluation presented in the previous section is based on deterministic modelling assumptions, in accordance with the Eurocode design methodology (EN 1991-1-2:2002 and EN 1992-1-2:2004). However, in contrast to the Eurocode guidance for normal design conditions, the target safety level for accidental design situations is not well-specified. To address this issue, Van Coile et al. [14] proposed target safety levels for structural fire design, based on a simplified cost-optimization model. Moreover, probabilistic methods are increasingly applied in fire safety engineering as a modification of more traditional design approaches, since these methods can more thoroughly take into account the uncertainties associated with the design and explicitly demonstrate the attainment of an adequate safety level [9]. Taking into account the uncertainties related to structural fire design is indispensable for evaluating the structural fire response of RC members. For example, it has been experimentally observed that both steel and concrete show considerable scatter in the value of their respective structural strengths at room temperature. Moreover, for both materials an even larger scatter is observed at the high temperatures typically associated with a building fire [15]. Indicative values for the uncertainties on the dimensions of concrete elements can be found in $[16,17]$.

To study the influence of the uncertainties related to the material properties and the geometry of fire exposed RC slabs, the burnout bending moment distribution is evaluated using Monte Carlo (MC) simulations. Figure 4. $a$ and $b$ depict the probability density function (PDF) and cumulative density function (CDF) for the burnout bending moment resistance $M_{R \text {, burnout }}$ of a RC slab, at ambient temperatures and for exposure to three Eurocode parametric fires regimes with a fixed fire load density $q_{f}$ and varying opening factor $O$. These graphs are obtained through repeated evaluation of Eq. (2) for $10^{5} \mathrm{MC}$ samples. In each sample, the slab configuration is characterized by a vector $X$ of randomly generated values of the probabilistic parameters listed in Table 2, with a reinforcement area $A_{s}=785 \mathrm{~mm}^{2}$. By generating many variable vectors $X$, calculating $M_{R \text {,burnout }}$ for each $X$ and analysing the results, the PDF and CDF of $M_{R, \text { burnout }}$ are obtained [18].

From these figures, it can be concluded that the mean bending moment resistance decreases with increasing fire load density and decreasing opening factor. Moreover, when lognormal curves are fitted to the obtained resistance distributions, the lognormal approximations are found to be an imperfect fit. In some cases, the lognormal approximation underestimates the frequency of low $M_{R \text {,burnout }}$ values, while in other cases it gives a crude overestimation. This phenomenon has been shown to be caused by the variability in the rebar axis distance $\sigma_{a}$ [12]. Moreover, the lognormal approximation appears to be worse for larger $\sigma_{a}$ and/or for lower rebar axis distances to the exposed surface.

Table 2. Stochastic models for RC slab variables.

\begin{tabular}{|c|c|c|c|c|}
\hline Property & Distribution & $\mu_{\mathbf{x}}$ & $\mathrm{COV}_{\mathrm{x}}$ & Ref. \\
\hline Concrete compressive strength $f_{c, 20^{\circ} \mathrm{C}}$ at $20^{\circ} \mathrm{C}$ & lognormal & $\begin{array}{l}42.9 \mathrm{MPa} \\
\left(f_{c k}+2 \sigma\right)\end{array}$ & 0.15 & {$[17]$} \\
\hline $\begin{array}{l}\text { Reinforcement yield stress } f_{y,(\theta)} \text { at } \theta^{\circ} \mathrm{C} \\
\left.\quad \text { (variation incorporated in } k_{f y(\theta)}\right)\end{array}$ & Deterministic & $560 \mathrm{MPa}$ & - & - \\
\hline $\begin{array}{c}\text { Retention factor } k_{f y(\theta)} \text { for the steel } \\
\text { yield stress at } \theta^{\circ} \mathrm{C}\end{array}$ & Logistic & $\begin{array}{l}\text { temperature } \\
\text { dependent }\end{array}$ & $\begin{array}{l}\text { temperature } \\
\text { dependent }\end{array}$ & {$[15]$} \\
\hline Slab height $h$ & Normal & $200 \mathrm{~mm}$ & $\begin{array}{c}0.025 \\
(\sigma=5 \mathrm{~mm})\end{array}$ & [17] \\
\hline Slab width $w$ & Deterministic & $1000 \mathrm{~mm}$ & - & - \\
\hline Bottom reinforcement area $A_{s}$ & Normal & $1.02 A_{s}$ & 0.02 & {$[17]$} \\
\hline Rebar axis distance $a$ & Beta $[\mu \pm 3 \sigma]$ & $35 \mathrm{~mm}$ & $\begin{array}{c}0.143 \\
\left(\sigma_{a}=5 \mathrm{~mm}\right)\end{array}$ & {$[16,17]$} \\
\hline
\end{tabular}





Figure 4: Burnout bending moment capacity $M_{R, \text { burnout }}$ and lognormal fitting curves for the RC slab specified in Table 2 , for exposure to Eurocode parametric fires with varying opening factor $O$.

\subsection{Probabilistic burnout bending resistance of RC slabs, with stochastic fire load density}

The previous Section 3.1 only considers the uncertain nature of the material properties and geometry of the slab. However, as no two compartments in a building are identically furnished, also the fire load density should be considered as a stochastic variable. Therefore, the above calculation is repeated with explicit consideration of the fire load density as defined in Annex E of EN 1991-1-2, see Table 3. Figure 5 depicts the PDF for the bending moment resistance of a slab as defined in Table 2, for a dwelling for a number of opening factors. In Figure 6, similar graphs are presented for office compartments.

Similar to the graphs in Figure 4, the results show that in compartments with a smaller opening factor, the average carrying capacity tends to be smaller. When comparing Figure $5 \mathrm{a}$ and $\mathrm{b}$, it is also evident that the average bending moment capacity reduces more in the case of a dwelling compared to an office compartment, as the average fire load density $\mu_{q, f}$ of the latter is higher, see Table 3 . Like the figures in the previous section, the lognormal approximations are found to be an imperfect fit.

Table 3. Stochastic models for Eurocode parametric fire variables.

\begin{tabular}{|c|c|c|c|c|}
\hline Property & Distribution & $\boldsymbol{\mu}_{\mathbf{x}}$ & $\mathbf{C O V}_{\mathbf{x}}$ & Ref. \\
\hline Fire load density for a dwelling $q_{f, \text { dwelling }}$ & Gumbel & $780 \mathrm{MJ} / \mathrm{m}^{2}$ & 0.3 & {$[11]$} \\
\hline Fire load density for an office $q_{f, \text { office }}$ & Gumbel & $420 \mathrm{MJ} / \mathrm{m}^{2}$ & 0.3 & {$[11]$} \\
\hline Opening factor $O$ & Deterministic & - & - & - \\
\hline
\end{tabular}





Figure 5: Burnout bending moment capacity $M_{R, \text { burnout }}$ and with lognormal fitting curves for the RC slab specified in Table 2 , for exposure to Eurocode parametric fires in dwelling compartments.
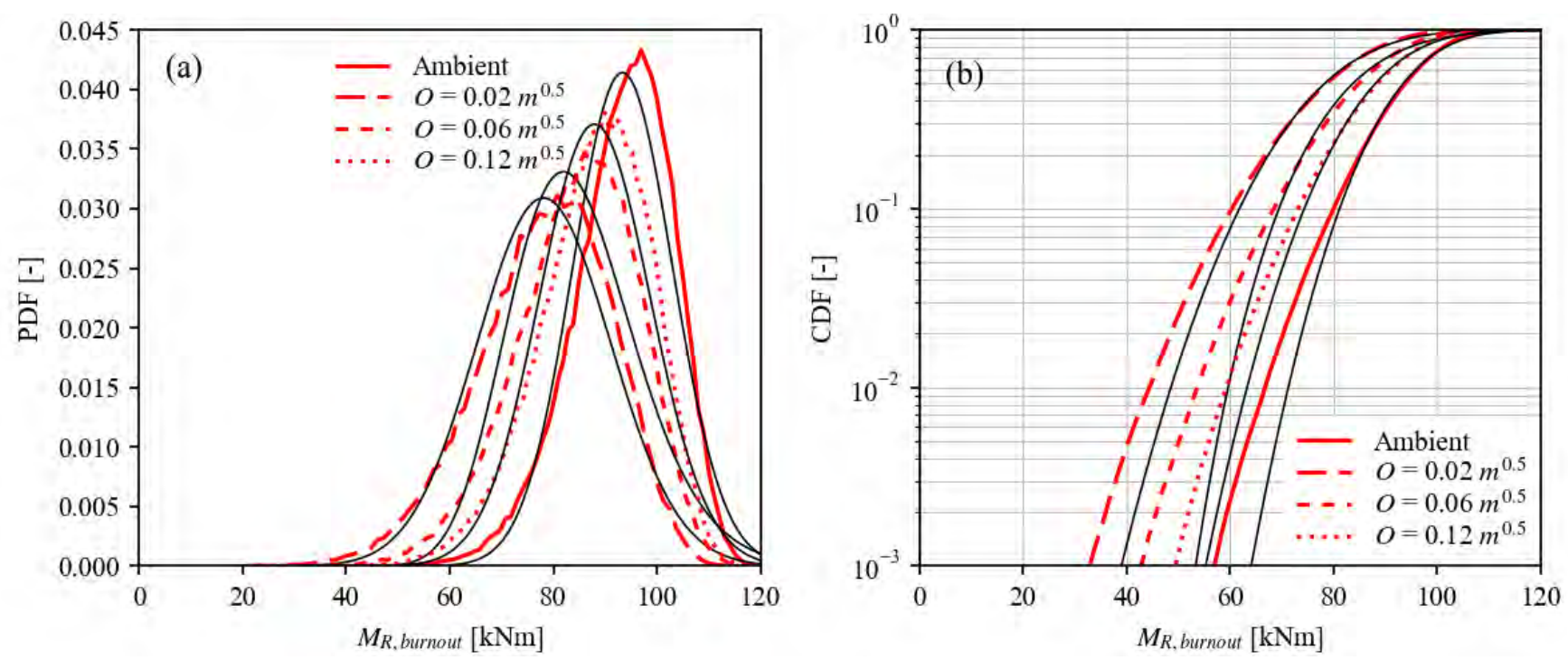

Figure 6: Burnout bending moment capacity $M_{R, \text { burnout }}$ and with lognormal fitting curves for the RC slab specified in Table 2 , for exposure to Eurocode parametric fires in office compartments.

\subsection{Failure probability of fire exposed RC slabs}

The stochastic formulation for the bending capacity must be combined with appropriate load models and model uncertainties to demonstrate a high reliability with respect to the attainment of burnout resistance. Then, the performance of the design can be demonstrated by comparing the obtained probability of failure $P_{f}$ to a specified target failure probability $P_{f, t}$. Previous studies investigating the failure probability of concrete slabs $[19,20]$ showed that in determining the capacity of the structure, the mechanical properties of steel at elevated temperatures cause large variations in the response.

Applied to the case of a simply supported fire exposed RC slab subjected to bending, and considering a functional requirement of structural resistance up to and including burnout, the probability of failure $P_{f}$ is defined as the probability of the bending moment due to load effect $M_{E, f i}$ exceeding the burnout bending moment capacity $M_{R, \text { burnout }}$ of the slab:

$$
P_{f}=P\left(K_{R} M_{R, \text { burnout }}<K_{E}\left(M_{G}+M_{Q}\right)\right)
$$

Herein, the load effect is considered as a combination of the moment $M_{G}$ induced by the permanent loads and the moment $M_{Q}$ induced by the applied variable load. $K_{E}$ and $K_{R}$ in this expression are the model 
uncertainties for respectively the load effect and the resistance effect. The probabilistic models for the model uncertainties and load effects are given in Table 4. By performing $10^{6}$ Monte Carlo simulations, and counting for which the realization of the resistance effect $K_{R} \cdot M_{R \text {,burnout }}$ is smaller than the realization of the load effect $K_{E} \cdot\left(M_{G}+M_{Q}\right)$, fragility curves for the burnout resistance of the slab as defined in Table 2 are obtained, as shown in Figure 7. Herein fragility curves are presented for three load ratios $\chi$, which defines the relation between the characteristic values $M_{G k}$ and $M_{Q k}$ :

$$
\chi=\frac{M_{Q k}}{M_{G k}+M_{Q k}}
$$

The fragility curves are plotted as a function of the fire design utilization $u_{f i}$, which for a RC slab in bending is defined as the ratio between the design load $M_{E d, f i}$ and design resistance $M_{R d, f i}$ in case of fire evaluated at ambient temperatures (i.e. $k_{f y}=1$ ):

$$
u_{f i}=\frac{M_{E d, f i}}{M_{R d, f i\left(20^{\circ} \mathrm{C}\right)}}=\frac{M_{G k}+\psi_{f i} M_{Q k}}{M_{R d, f i\left(20^{\circ} \mathrm{C}\right)}}
$$

The partial factors in the expression for $M_{E d, f i}$ are equal to unity and the combination factor $\psi_{f i}=0.3$ for the variable load, i.e. the recommended value for residential and office buildings. From the graphs it is clear that both the opening factor $\mathrm{O}$ and load ratio have a significant influence on the failure probability of $\mathrm{RC}$ slabs exposed to Eurocode parametric fires.

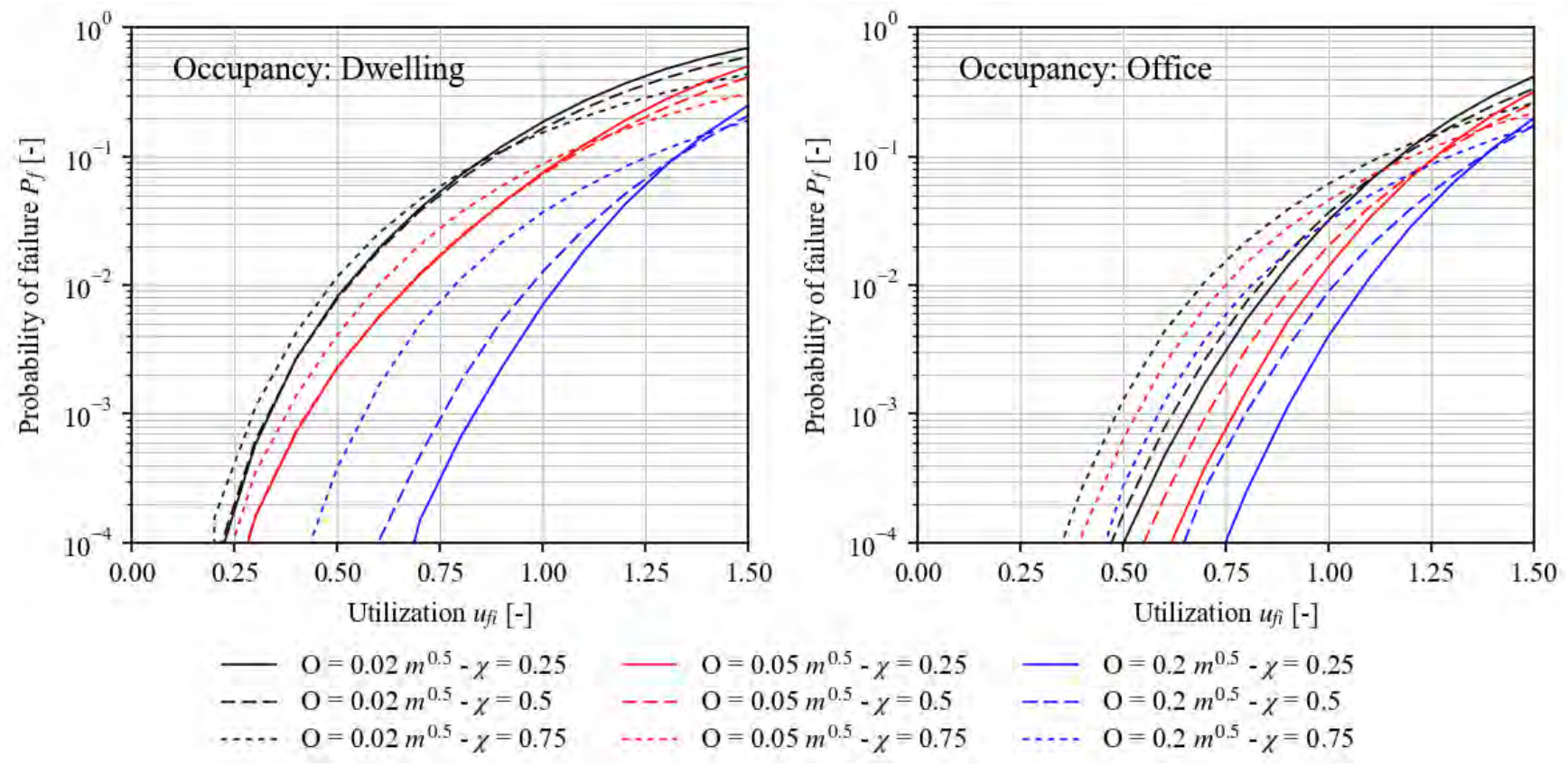

Figure 7: Fragility curves for RC slabs exposed to natural fires with varying opening factor O, for Dwellings and Offices

Table 4. Stochastic models for load variables and model uncertainties.

\begin{tabular}{|c|c|c|c|c|}
\hline Property & Distribution & $\boldsymbol{\mu}_{\mathbf{x}}$ & $\mathbf{C O V}_{\mathbf{x}}$ & Ref. \\
\hline Moment $M_{G}$ induced by the permanent load & Normal & $M_{G k}$ & 0.1 & {$[21]$} \\
\hline $\begin{array}{c}\text { Moment } M_{Q} \text { induced by the variable load } \\
\text { (arbitrary point in time) }\end{array}$ & Gamma & $0.2 M_{Q k}$ & 0.95 & {$[21]$} \\
\hline Model uncertainty $K_{E}$ for the load effect & Lognormal & 1 & 0.1 & {$[21]$} \\
\hline Model uncertainty $K_{R}$ for the resistance effect & Lognormal & 1.2 & 0.15 & {$[17]$} \\
\hline
\end{tabular}




\section{GLOBAL RESISTANCE FACTOR FOR RC SLABS EXPOSED TO NATURAL FIRE}

As specified in the introduction, the global resistance factor (GRF) $\gamma_{R}$ allows to perform a reliability-based evaluation, considering a single model evaluation using mean values for the stochastic variables. The design value for the resistance effect $R_{d}$ is then obtained through eq. (1). Applied to the situation of RC slabs subject to bending, the attainment of the target safety level is then confirmed through eq. (6), where $\mu_{R, \text { burnout }}$ is the evaluation of eq. (2) considering the expected values for the stochastic variables.

$$
\frac{\mu_{R, \text { burnout }}}{\gamma_{R}}=M_{R d, f i}>M_{E d, f i}=M_{G k}+\psi_{f i} M_{Q k}
$$

In case the resistance effect $R_{d}$ can be neatly approximated by a lognormal distribution, the GRF $\gamma_{R}$ can be approximated directly using a simple expression based on the coefficient of variation $\mathrm{V}_{R}$ as applied in [8]. However, as shown in Figure 4, 5 and 6 a lognormal approximation is not appropriate for the burnout resistance of RC slabs exposed to parametric fires. Therefore, this article applies an alternative calculation method, which uses a large number of Monte Carlo simulations and a full-probabilistic analysis to determine directly the actual value of the GRF for the bending moment capacity of concrete slabs exposed to fire.

Figure 8 depicts the calculated values of the GRF for the slab configuration in Table 2, exposed to several Eurocode parametric fire regimes, for various target failure probabilities $p_{f, t}$ and load ratios $\chi$. In accordance with the Eurocode, for dwellings and offices, the combination factor for the variable load was set to $\psi_{f i}=0.3$.

Overall, the graphs show that the highest values for the GRF are obtained for the case of a dwelling; compared to the case for offices, the GRF is higher over the entire range of studied opening factor values. For both compartment types, the GRF reduced significantly with increasing opening factor. Furthermore, the load ratio is shown to have a significant influence on the GRF. This is especially the case for $\chi=0.75$ (i.e. $M_{Q k}=3 \cdot M_{G k}$ ), where consistently higher GRF values are observed over the entire range of opening factor values.
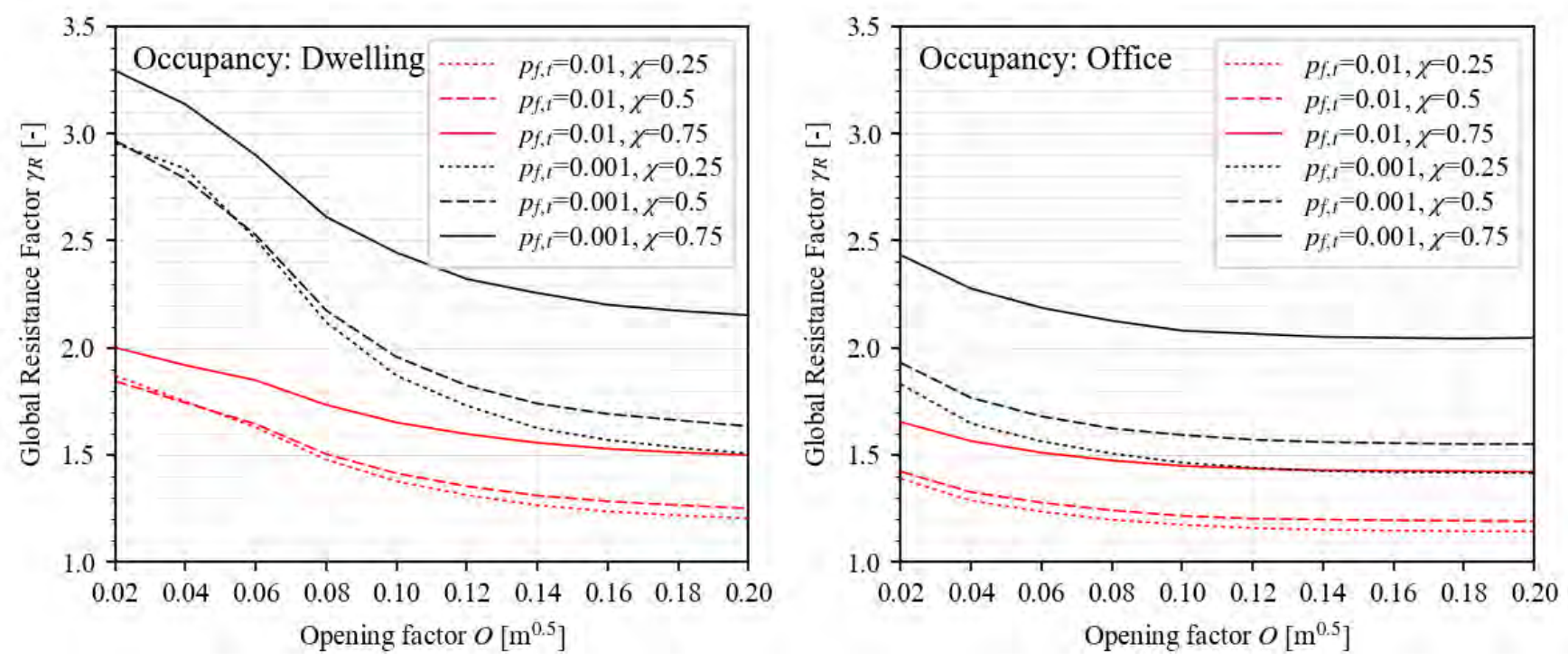

Figure 8: GRF for simply supported RC slabs exposed to natural fire, for various load ratios and target failure probabilities, over a range of fire opening factors.

\section{EQUIVALENCY EXPRESSION}

The above calculations were obtained assuming a $10 \mathrm{~m} \times 10 \mathrm{~m} \times 3 \mathrm{~m}$ reference compartment with an opening factor $O=0.05 \mathrm{~m}^{1 / 2}$, fire load density $q_{f}=800 \mathrm{MJ} / \mathrm{m}^{2}$ and thermal effusivity $b=1450 \mathrm{~J} / \mathrm{m}^{2} \mathrm{~s}^{0.5}$. However, as shown in [6], these results can be generalized for any compartment within the boundaries defined in EN1991-1-2 annex A, using the following scaling expressions (7) and (8). 


$$
\begin{gathered}
O_{e q}=O \cdot \frac{b_{e q}}{b} \\
q_{f, e q}=q \cdot \frac{A_{f}}{A_{f, e q}} \cdot \frac{A_{t, e q}}{A_{t}} \cdot \frac{b_{e q}}{b}
\end{gathered}
$$

These expressions are based on the fact that any parametric fire in a generic compartment with a given set of geometric and thermal properties is identical to the temperature-time curve in a reference compartment with an invariant geometry and invariant thermal properties when considering appropriate equivalent values for the fire load density $q_{f, e q}$ and opening factor $O_{e q}$ for this equivalent compartment [22]. The suffix ' $e q$ ' refers to the equivalent compartment with fixed geometry and thermal inertia, while the other parameters refer to the generic compartment.

Using the above expressions, the calculated values presented in Figure 8 are applicable to any compartment within the Eurocode parametric fire framework. They can therefore easily be implemented as part of a more elaborate GRF based design method, as presented in [6].

\section{CONCLUSIONS}

The concept of a global resistance factor (GRF) for concrete slabs exposed to Eurocode parametric fire, including a cooling phase, was presented and the GRF values were computed for different target failure probabilities and for a several compartment types, over the entire range of opening factor values defined in the Eurocodes. Application of the determined GRF allows for explicit safety evaluations for fire exposed concrete slabs, without requiring the application of expert probabilistic methods. Lastly, a procedure for scaling these results to a compartment of different dimensions and thermal properties was presented. Through this procedure, the obtained GRF values can be incorporated in a simple design check for a wide range of compartment configurations.

\section{ACKNOWLEDGMENT}

The authors wish to thank the Research Foundation of Flanders (FWO) for the financial support on the research project "Performance-based analysis and design for enhancing the safety of prestressed concrete hollow-core slabs in case of fire and unforeseen events".

\section{REFERENCES}

1. Organization International for Standardization, (1975). ISO 834-1975. Fire resistance tests- elements of building construction

2. American Society for Testing and Materials, (2008). ASTM Standard methods of fire test of building construction and materials. Test Method E119a -08. West Conshohocken, PA

3. CEN, (2004). EN 1992-1-2. Eurocode 2 - design of concrete structures. Part 1-2: general rules - structural fire design. Brussels

4. Gernay, T, (2019). Fire resistance and burnout resistance of reinforced concrete columns. Fire Safety Journal 104:67-78. https://doi.org/10.1016/j.firesaf.2019.01.007

5. Salah Dimia, M, Guenfoud, M, Gernay, T, Franssen, JM, (2011). Collapse of concrete columns during and after the cooling phase of a fire. Journal of Fire Protection Engineering 21:245-263. https://doi.org/10.1177/1042391511423451

6. Thienpont, T, Van Coile, R, Caspeele, R, De Corte, W, Burnout resistance of concrete slabs: probabilistic assessment and global resistance factor calibration. Fire Safety Journal (in review)

7. Cervenka, V, (2008). Global Safety Format for Nonlinear Calculation of Reinforced Concrete. Beton- und Stahlbetonbau 103:37-42. https://doi.org/10.1002/best.200810117

8. Van Coile, R, Caspeele, R, Taerwe, L, (2012). Global Resistance factor for concrete slabs exposed to fire. In: Fontana M, Frangi A, Knobloch M (eds) 7th International Conference on Structures in Fire. Zurich

9. Thienpont, T, Van Coile, R, De Corte, W, Caspeele, R, (2019). Determining a Global Resistance Factor for 
simply supported fire exposed RC slabs. In: Proceedings of the fib Symposium 2019. Krakow, pp 2191-2197

10. Allaix, DL, Carbone, VI, Mancini, G, (2013). Global safety format for non-linear analysis of reinforced concrete structures. Structural Concrete 14:29-42. https://doi.org/10.1002/suco.201200017

11. CEN, (2002). EN 1991-1-2. Eurocode 1: actions on structures - Part 1-2: general actions - actions on structures exposed to fire. Brussels

12. Van Coile, R, Caspeele, R, Taerwe, L, (2013). The mixed lognormal distribution for a more precise assessment of the reliability of concrete slabs exposed to fire. In: Safety, Reliability and Risk Analysis. pp 2693-2699

13. Van Coile, R, (2015). Reliability-Based Decision Making for Concrete Elements Exposed to Fire. Ghent University

14. Van Coile, R, Hopkin, D, Bisby, L, Caspeele, R, (2017). The meaning of Beta: Background and applicability of the target reliability index for normal conditions to structural fire engineering. Procedia Engineering 210:528-536. https://doi.org/10.1016/j.proeng.2017.11.110

15. Qureshi, R, Ni, S, Khorasani, NE, Van Coile, R, Gernay, T, Hopkin, D, (2020). Probabilistic models for temperature dependent strength of steel and concrete. Journal of Structural Engineering 146:

16. The Joint Committee on Structural Safety, (2001). Probabilistic Model Code - Part 3.10: Dimensions. JCSS

17. Holicky, M, (2009). Reliability analysis for structural design. SUN MeDIA Stellenbosch

18. Ang, AHS, Tang, WH, (2007). Probability concepts in engineering, 2nd ed. John Wiley \& Sons, New York

19. Ioannou, I, Aspinall, W, Rush, D, Bisby, L, Rossetto, T, (2017). Expert judgment-based fragility assessment of reinforced concrete buildings exposed to fire. Reliability Engineering and System Safety 167:105-127. https://doi.org/10.1016/j.ress.2017.05.011

20. Gernay, T, Khorasani, NE, Garlock, M, (2019). Fire Fragility Functions for Steel Frame Buildings: Sensitivity Analysis and Reliability Framework. Fire Technology 55:1175-1210. https://doi.org/10.1007/s10694-0180764-5

21. Jovanović, B, Van Coile, R, Hopkin, D, Elhami Khorasani, N, Lange, D, Gernay, T, (2020). Review of Current Practice in Probabilistic Structural Fire Engineering: Permanent and Live Load Modelling. Fire Technol. https://doi.org/10.1007/s10694-020-01005-w

22. Thienpont, T, Van Coile, R, Caspeele, R, De Corte, W, (2019). Comparison of fire resistance and burnout resistance of simply supported reinforced concrete slabs exposed to parametric fires. In: Proceedings of CONFAB 2019. London 